\title{
The Relationship Between Sleep Duration and Sleep Quality and Body Mass Index in Young People
}

\author{
Preeti Gupta $^{1}$, Sunita Tiwari ${ }^{2}$, Neena Srivastava ${ }^{3}$, Vani Gupta ${ }^{4}$ \\ ${ }^{1}$ Junior Resident (MD) Department of Physiology, King George's Medical University, Lucknow, UP, India \\ gpreeti12841@gmail.com \\ ${ }^{2}$ Professor and Head, Department of Physiology, King George's Medical University, Lucknow, UP, India \\ ${ }^{3}$ Professor, Department of Physiology, King George's Medical University, Lucknow, UP, India \\ ${ }^{4}$ Professor, Department of Physiology, King George's Medical University, Lucknow, UP, India
}

\begin{abstract}
Background: As it is evident from the research in recent years that short sleep has been found as a risk factor for obesity. However, we still need enough evidence in this field. Therefore, we explored the directionality of the association between sleep duration and sleep quality with body mass index. Aims \& Objectives: Aims: To evaluate the link of sleep duration and sleep quality with BMI among young adults. Objectives (a) To assess the association of sleep duration with BMI. (b)To assess the quality of sleep with BMI. Methods: In this cross-sectional study, 88 individuals selected from King George's Medical University were taken as participants. Majority of patients were males (67\%). There were 29 (33.0\%) females. Sex ratio of study was 2.03we used Pittsburgh sleep quality index (PSQI) questionnaire to assess time spent in bed and sleep quality. Body mass index was divided into 3categories.Underweight $\left(B M I<18.5 \mathrm{Kg} / \mathrm{m}^{2}\right)$ Normal weight $\left(18.5-22.9 \mathrm{~kg} / \mathrm{m}^{2}\right)$, Overweight $\left(23-24.9 \mathrm{~kg} / \mathrm{m}^{2}\right)$ Obese grade $\mathrm{I}\left(25-34.9 \mathrm{~kg} / \mathrm{m}^{2}\right)$, Obese grade II $\left(35.0 \mathrm{~kg} / \mathrm{m}^{2}\right)$ and above. Results: We observed that short sleep duration $\pm S D(\mathrm{hr})<6 \mathrm{hrs} /$ day $f=9.04 ; p<0.001$ is associated with greater chances of being overweight and obese and mean sleep quality(mean PSQI $\pm S D) f=12.24 ; p<0.001$ was poor in obese grade I and obese II. Conclusion: This study concludes that short sleep duration and poor sleep quality were associated with overweight obesity among young adults.
\end{abstract}

Keywords: PSQI, BMI, sleep quality, sleep duration, obese

\section{Introduction}

Importance of sleep, both in terms of adequacy as well as quality has been emphasized upon for the maintenance of physical as well as psychological well-being of the all the living beings in general and human beings in particular Sleep helps to update the brain as well as other bodily mechanisms such as metabolism, appetite regulation, immune system, hormonal and cardiovascular system. The importance of sleep in maintenance of good health, particularly that of adolescents and young adults is widely being recognized in recent years in view of changing lifestyle, growing emphasis on night-life, television, media and internet use [1, 2]. Sleep is now being considered a critical component of healthy development and well-being $[3,4,5]$.

A healthy sleep is characterized by adequacy of sleep duration, good quality, appropriate timing and freedom from sleep disorders [6, 7]. A healthy human adult requires an average of 7-9 hours of sleep per day [8]. Adults sleeping for shorter duration show higher BMI, increased weight and neck circumference compared to those who sleep 8hrs/day emphasizing the association between short sleep duration, BMI and central adiposity ${ }^{3}$.Body mass index (BMI) is considered as an indicator of general health. Moreover, it is also considered to be an indicator of lifestyle. While most of the times the association between body mass index and sleep are studied at a stage when they take form of a disorder or in an altered state of health, there are limited studies to assess the sleep pattern in context with body mass index in otherwise healthy adults. There is an extreme risk to the population of young adults as their lifestyle and academic demands can lead to insufficient sleep duration as well as sleep quality.

\section{Materials and Methods}

The present study was carried out at Department of Physiology, King George's Medical University, Lucknow.

Study design was Cross sectional study 88 cases were included in the study. The study was carried out as per the guidelines of good medical research as ensued by Helsinki Declaration. Participation in study was entirely voluntary and the participants were included in the study after obtaining informed consent following detailed description about the study procedure and possible benefits and risks involved. The project was approved by Institutional Ethics Committee too before the enrolment of participants began. Apparently healthy adults were taken with age group as 20 40 yrs, without diabetes, hypertension, renal disease, psychiatric problems, and those who were not taking medication of any sort, any other chronic illness.

\subsection{Methodology}

Participants were selected from amongst the apparently healthy individuals visiting the facility, medical students after explaining the purpose of study and sleep assessment procedure, a total of 88 willing volunteers were invited for the sleep assessment. The sample size was calculated using following (Daniel, 1999) [9] 
Weight and height of the volunteers were measured, neck circumference and waist circumference were also measured. Body mass index was calculated using the formula:

$$
\mathrm{BMI}=\text { Weight }(\text { in } \mathrm{kg}) / \text { Height in } \text { meter }^{2}
$$

On the basis of body mass index, the volunteers were categorized as follows using the definitions of obesity proposed for Asian Indians [10, 11]: Underweight (BMI < $18.5 \mathrm{~kg} / \mathrm{m}^{2}$ ), Normal weight (BMI 18.5-22.9 $\mathrm{kg} / \mathrm{m}^{2}$ ), Overweight (BMI 23.0-24.9 kg/m²), Obese Grade I (BMI 25.0-34.9 kg/m²), Obese Grade II (BMI >35.0 kg/m²), The sleep assessment was done using: Pittsburgh Sleep Quality Index (PSQI).

\section{Sleep quality}

The screening of sleep quality was done using Pittsburgh Sleep Quality Index (PSQI). PSQI is a 19-item inventory with each item having a score ranging from 0 to 3 with higher score indicating more severe sleep problem. The 19 items are grouped into 7 components. The sleep component scores are summed to yield a total score ranging from 0 to 21 with the higher total score (referred to as global score) indicating worse sleep quality. In distinguishing good and poor sleepers, a global PSQI score > 5 was considered to be indicator of sleep disturbances [12]. The grading of quality of sleep using PSQI was done as follow Score <5- No sleep problem, Score 5-10-Mild disturbances Score >10 Moderate-to-severe disturbances

\section{Sleep Duration}

The duration of sleep was taken according to PSQI (Pittsburgh sleep quality index) questionnaire .self reported and time spent in bed was calculated 'GO TO BED 'TIME being subtracted from 'GET UP TIME'. Numerical value of sleep duration calculated by substracting time spent in bed with sleep latency. Subjective sleep latency has been calculated by asking PSQI questionnaire the value being subtracted from time spent in bed calculated total sleep duration numerical value was divided into categories 1 . $<6$ $\mathrm{hr}$, 2.6-7 hr, 3.7-9 hr We took 7-9 hrs as referent value a $<7$ $\mathrm{hrs}$ and $\geq 9 \mathrm{hrs}$ in young adults has negative consequences to health such as metabolic ,cardiovascular and musculoskeletal disorders.

\section{Data Analyses}

Data analysis was done using SPSS (Statistical package for Social Sciences) Version 21.0 statistical analysis software. Chi-square test, ANOVA and Pearson correlationcoefficient were used to analyze the data. A 'p' value less than 0.05 was considered as significant. Strength of bivariate correlation using Pearson correlation coefficient was considered as weak at an ' $r$ ' value $<0.3$, mild at ' $r$ ' value $0.3-0.5$, moderate at ' $r$ ' value $0.5-0.7$ and strong at ' $r$ ' value $>0.7$. The ' + ' or ' - ' sign before ' $r$ ' value denoted positive/direct or negative/inverse correlations.

\section{Results}

Table 1.shows the demographic profile as well as sleep quality measured through PSQI characteristics of the study population.
In Table 2, Majority of participants in all the BMI categories except for Obese Grade II were males. In Obese Grade II BMI category, majority of participants were females $(56.3 \%)$. However, on evaluating the data statistically, the difference was not found to be significant ( $\mathrm{p}=0.077)$.

In table 3, Majority of patients in normal weight category had PSQI score <5 (63.2\%) as compared to $35.7 \%$ overweight, $5.1 \%$ obese grade I and $6.3 \%$ obese grade II patients. On the other hand, proportion of those with PSQI $>10$ was $0 \%, 7.1 \%, 38.5 \%$ and $43.8 \%$ respectively in normal weight, overweight, obese grade I and obese grade II categories. Statistically, with increasing BMI category, the proportion of those with PSQI $>5$ showed a significant increase $(\mathrm{p}<0.001)$.

Mean PSQI scores of normal weight, overweight, obese grade I and obese grade II subjects were $4.53 \pm 1.50$, $6.07 \pm 2.46,8.82 \pm 2.70$ and $9.50 \pm 3.14$ respectively, thus showing a significant incremental trend with increasing BMI $(\mathrm{p}<0.001)$

Table 4, Statistically, with increasing BMI category, the proportion of those with PSQI $>5$ showed a significant increase $(\mathrm{p}<0.001)$ Mean PSQI scores of normal weight, overweight, obese grade I and obese grade II subjects were $4.53 \pm 1.50, \quad 6.07 \pm 2.46, \quad 8.82 \pm 2.70$ and $9.50 \pm 3.14$ respectively, thus showing a significant incremental trend with increasing BMI $(\mathrm{p}<0.001)$

\section{Discussion}

Sleep is an active state of unconsciousness produced by the body where the brain is in a relative state of rest and is reactive primarily to internal stimulus [13]. Importance of sleep, both in terms of adequacy as well as quality has been emphasized upon for the maintenance of physical as well as psychological well-being of all the living beings in general and human beings in particular. Sleep helps to update the brain as well as other bodily mechanisms such as metabolism, appetite regulation, immune system, hormonal and cardiovascular system $[14,15]$. The duration and quality of sleep of an individual is affected by a number of factors including genetic, environmental, occupational, lifestyle and health status.

Body mass index (BMI) is considered as an indicator of general health $[16,17]$. Both underweight and overweight/obese conditions have been shown to be associated with vitiated health and lifestyle. While most of the times the association between body mass index and sleep are studied at a stage when they take form of a disorder or in an altered state of health. There are limited studies to assess the sleep pattern in context with body mass index in otherwise healthy individuals.

Hence the present study was carried out with an aim to find out association between sleep duration and sleep quality with body mass index. The association of sleep quality with body mass has been assessed in a varied population profile in different studies conducted in recent years. Most of these studies have been performed in young adults aged 20 to 30 years and mean age below 30 years as they have mainly 
been conducted in college going or medical students. In present study, we went beyond this age profile and studied it in a rather diversified adult population that not only included student volunteers but other volunteers too. The purpose was not to restrict the study in a set of student population of young adults but to include young adults in general. Moreover, it was also assumed that including an all-student young adult population gives a biased view of picture as young adults, particularly medical students, owing to their study compulsions have altered sleep behaviours which cannot be generalized as a representative of adults but is specifically related with that particular group of population only.

With respect to use of tools to study the sleep pattern, in present study we used both screening tool (PSQI) . it is one of the popular tools for screening purposes and has been used extensively in different studies to study the sleep pattern in young adultsError! Bookmark not defined.'Error! Bookmark not defined.'Error! Bookmark not defined.'Error! Bookmark not defined.'Error! Bookmark not defined.'Error! Bookmark not defined.'Error! Bookmark not defined.'Error! Bookmark not defined.'Error! Bookmark not defined.'Error! Bookmark not defined.'Error! Bookmark not defined.. PSQI covers 7-different domains to calculate a comprehensive sleep patternIn present study we found that proportion of those with PSQI score $>5$ was $63.8 \%, 64.3 \%, 94.9 \%$ and $93.7 \%$ respectively in normal weight, overweight, obese grade I and obese grade II subjects respectively. Mean PSQI of normal weight, overweight, obese grade I and obese grade II subjects were $4.53 \pm 1.50,6.07 \pm 2.46, \quad 8.82 \pm 2.70$ and $9.50 \pm 3.14$ respectively, thus showing a significant incremental trend with increasing BMI. Findings similar to present study have been shown in other studies too. Kumar and Nagar (2017)Error! Bookmark not defined. in their study found that majority of overweight and obese students had PSQI $\geq 7$ whereas majority of underweight and normal weight students had PSQI <7. A significant incremental trend of higher PSQI with increasing body mass index was also seen by Israel et al.Error! Bookmark not defined. in their study. Young et al. (2020)Error! Bookmark not defined. in their study among 463 young adult women aged 23 years also found PSQI $>5$ to be associated with higher mean body mass index..

Body mass index of study population in our study ranged from 18.02 to $48.77 \mathrm{~kg} / \mathrm{m}^{2}$. According to BMI criteria used, $2(2.3 \%)$ were underweight, $17(19.3 \%)$ were in normal weight, $14(15.9 \%)$ were in overweight, $39(44.3 \%)$ were in obese grade I and $16(18.2 \%)$ were in obese grade II category. Mean BMI of study population was $28.52 \pm 6.36$ $\mathrm{kg} / \mathrm{m}^{2}$. Thus the present study was marked by a high prevalence of overweight and obese participants. One of the reasons for this high prevalence of overweight and obese participants could be the utilization of Body Mass Index criteria proposed for Asian IndiansError! Bookmark not defined.'Error! Bookmark not defined. which tends to classify obesity at a Body mass index of $25.0 \mathrm{~kg} / \mathrm{m}^{2}$ itself. Compared to present study that had 69/88 (78.4\%) overweight and obese participants, Vargas et al. (2014)Error! Bookmark not defined. in their study had only $33.3 \%$ overweight and obese participants. Israel et al.Error! Bookmark not defined. too had only $24 \%$ participants in obese category using BMI $>30 \mathrm{~kg} / \mathrm{m}^{2}$ as the criteria for such differentiation. However, Khullar et al.Error! Bookmark not defined. who used criteria similar to ours reported the proportion of overweight and obese in their study as $49.3 \%$, still in their study as many as $17.2 \%$ underweight participants were enrolled.

In present study, no significant difference among different BMI categories was observed for age and sex, thus indicating that the confounding effect of these factors, if any, was even in all the BMI categories.

Sleep disturbance, which negatively impacts chronobiology of hormonal rhythms and metabolism, is also associated with obesity, insulin insensitivity, diabetes, hormonal imbalance, and appetite dysregulation. Circadian disruption, typically induced by shift work and sleep disturbance, may also have a negative effect on health due to impaired glucose and lipid homeostasis, reversed melatonin and cortisol rhythms, and loss of clock gene rhythmicityError! Bookmark not defined. Thus impact of lifestyle as well as occupational commitments on sleep pattern as well as on BMI could not be ignoredError! Bookmark not defined.'Error! Bookmark not defined.. All these relationships are complex and need a larger sample size with inclusion of more variables to study this relationship further. Hence, we recommend further studies on a larger sample size, preferably with a longitudinal design to evaluate these relationships further

\section{Limitations of Study}

1) A larger sample size is needed for the study for sleep quality.

2) An objective assessment is more appropriate to assess sleep duration by knowing the sleep latency

3) One of the reasons for absence of a strong positive correlation between PSQI and BMI in our study may be the fact that we had relatively fewer cases in lower BMI category.,

4) In underweight category we had only 2 (2.3\%) cases which probably were too fewer to have an independent existence.

\section{Conclusion}

The present study was carried out to assess the association between sleep duration, quality and body mass index. For this purpose, a total of 88 subjects (20-40 Years; Mean age $32.55 \pm 6.40$ Years; $67 \%$ males) were enrolled in the study and were divided according to their BMI status and their sleep pattern was studied using Pittsburgh sleep Quaity Index (PSQI). Following were the key findings of the study:

1) Body mass index of study population ranged from 18.02 to $48.77 \mathrm{~kg} / \mathrm{m}^{2}$. According to BMI criteria used, 2 $(2.3 \%)$ were underweight, $17(19.3 \%)$ were normal weight, $14(15.9 \%)$ were overweight, $39(44.3 \%)$ were obese grade I and $16(18.2 \%)$ were obese grade II 
category. Mean BMI of study population was $28.52 \pm 6.36 \mathrm{~kg} / \mathrm{m}^{2}$

2) No significant difference in mean age and gender profile of subjects in different BMI categories was observed

3) Proportion of those with PSQI score $>5$ was $63.8 \%$, $64.3 \%, 94.9 \%$ and $93.7 \%$ respectively in normal weight, overweight, obese grade I and obese grade II subjects respectively. Mean PSQI of normal weight, overweight, obese grade I and obese grade II subjects were $4.53 \pm 1.50, \quad 6.07 \pm 2.46, \quad 8.82 \pm 2.70$ and $9.50 \pm 3.14$ respectively, thus showing a significant incremental trend with increasing BMI.

4) There was a mild significance between total sleep duration and BMI. Persons sleeping $<6 \mathrm{hr}$ tend to have higher BMI than those sleeping for 7-9 hrs.

Table 1: Demographic Profile, Anthropometric and Sleep Characteristics of Study population

\begin{tabular}{|c|c|c|}
\hline SN & Characteristic & Statistic \\
\hline 1. & Mean Age \pm SD (Range) in years & $32.55 \pm 6.40(20-40)$ \\
\hline 2. & $\begin{array}{c}\text { Sex } \\
\text { Male } \\
\text { Female }\end{array}$ & $\begin{array}{l}59(67.0 \%) \\
29(33.0 \%)\end{array}$ \\
\hline 3. & $\begin{array}{c}\text { Body mass index }\left(\text { BMI) }\left(\mathrm{kg} / \mathrm{m}^{2}\right)\right. \\
\text { Underweight }\left(\text { BMI }<18.5 \mathrm{~kg} / \mathrm{m}^{2}\right) \\
\text { Normal weight }\left(\text { BMI } 18.5-22.9 \mathrm{~kg} / \mathrm{m}^{2}\right) \\
\left.\text { Overweight (BMI } 23.0-24.9 \mathrm{~kg} / \mathrm{m}^{2}\right) \\
\left.\text { Obese Grade I (BMI } 25.0-34.9 \mathrm{~kg} / \mathrm{m}^{2}\right) \\
\left.\text { Obese Grade II (BMI }>35.0 \mathrm{~kg} / \mathrm{m}^{2}\right) \\
\text { Mean BMI } \pm \text { SD }\left(\text { Range) } \mathrm{kg} / \mathrm{m}^{2}\right.\end{array}$ & $\begin{array}{c}2(2.3 \%) \\
17(19.3 \%) \\
14(15.9 \%) \\
39(44.3 \%) \\
16(18.2 \%) \\
28.52 \pm 6.35(18.02-48.77)\end{array}$ \\
\hline 4. & $\begin{array}{c}\text { Mean PSQI } \pm \text { SD (Range) } \\
<5 \\
\geq 5\end{array}$ & $\begin{array}{c}7.58 \pm 3.17(3-13) \\
20(22.7 \%) \\
68(77.3 \%)\end{array}$ \\
\hline
\end{tabular}

Table 2: Comparison of Demographic Profile and anthropometric parameters of patients in different BMI categories

\begin{tabular}{|c|c|c|c|c|c|c|}
\hline SN & Characteristic & $\begin{array}{c}\text { Normal weight } \\
(\mathrm{n}=19)\end{array}$ & $\begin{array}{c}\text { Overweight } \\
(\mathrm{n}=14)\end{array}$ & $\begin{array}{c}\text { Obese Grade I } \\
(\mathrm{n}=39)\end{array}$ & $\begin{array}{c}\text { Obese Grade II } \\
(\mathrm{n}=16)\end{array}$ & Statistical significance \\
\hline 1. & Mean age \pm SD (years) & $30.00 \pm 6.09$ & $31.64 \pm 7.30$ & $33.51 \pm 5.97$ & $34.00 \pm 6.52$ & $\mathrm{~F}=1.711 ; \mathrm{p}=0.171$ \\
\hline 2. & Gender & & & & & \\
& Male & $12(63.2 \%)$ & $9(64.3 \%)$ & $31(79.5 \%)$ & $7(43.8 \%)$ & $\chi^{2}=6.84 ; \mathrm{p}=0.077$ \\
& Female & $7(36.8 \%)$ & $5(35.7 \%)$ & $8(20.5 \%)$ & $9(56.3 \%)$ & \\
\hline
\end{tabular}

Table 3: Comparison of PSQI scores among different BMI categories

\begin{tabular}{|c|c|c|c|c|c|c|}
\hline SN & PSQI Scores & $\begin{array}{c}\text { Normal weight } \\
(\mathrm{n}=19)\end{array}$ & $\begin{array}{c}\text { Overweight } \\
(\mathrm{n}=14)\end{array}$ & $\begin{array}{c}\text { Obese Grade I } \\
(\mathrm{n}=39)\end{array}$ & $\begin{array}{c}\text { Obese Grade II } \\
(\mathrm{n}=16)\end{array}$ & $\begin{array}{c}\text { Statistical } \\
\text { significance }\end{array}$ \\
\hline 1. & $<5$ & $12(63.2 \%)$ & $5(35.7 \%)$ & $2(5.1 \%)$ & $1(6.3 \%)$ & \multirow{3}{*}{$\chi^{2}=34.07 ; p<0.001$} \\
\hline 2. & $5-10$ & $7(36.8 \%)$ & $8(57.1 \%)$ & $22(56.1 \%)$ & $8(50.0 \%)$ & \\
\hline 3. & $>10$ & 0 & $1(7.1 \%)$ & $15(38.5 \%)$ & $7(43.8 \%)$ & \\
\hline & Mean PSQI \pm SD & $4.53 \pm 1.50$ & $6.07 \pm 2.46$ & $8.82 \pm 2.70$ & $9.50 \pm 3.14$ & $F=16.84 ; p<0.001$ \\
\hline
\end{tabular}

Table 4: Association of BMI with Sleep Duration and Quality

\begin{tabular}{|c|c|c|c|c|c|c|}
\hline SN & Parameter & $\begin{array}{c}\text { Under-weight/ } \\
\text { Normal weight }(\mathrm{n}=18)\end{array}$ & $\begin{array}{c}\text { Over-weight } \\
(\mathrm{n}=6)\end{array}$ & $\begin{array}{l}\text { Obese Grade I } \\
(n=47)\end{array}$ & $\begin{array}{c}\text { Obese Grade II } \\
(\mathrm{n}=17)\end{array}$ & $\begin{array}{c}\text { Statistical } \\
\text { significance }\end{array}$ \\
\hline \multirow{4}{*}{1.} & Mean Sleep duration $\pm \mathrm{SD}(\mathrm{hr})$ & $8.00 \pm 0.59$ & $7.08 \pm 0.74$ & $6.85 \pm 0.95$ & $6.62 \pm 0.99$ & $\mathrm{~F}=9.04 ; \mathrm{p}<0.001$ \\
\hline & $<6 \mathrm{hr}$ & 0 & 0 & $4(8.5 \%)$ & $4(23.5 \%)$ & \multirow{3}{*}{$\chi^{2}=19.66 ; p=0.003$} \\
\hline & $6-7 \mathrm{hr}$ & 0 & $2(33.3 \%)$ & $19(40.4 \%)$ & $6(35.3 \%)$ & \\
\hline & $7-9 \mathrm{hr}$ & $18(100 \%)$ & $4(66.7 \%)$ & $24(51.1 \%)$ & $7(41.2 \%)$ & \\
\hline
\end{tabular}

\begin{tabular}{|c|c|c|c|c|c|c|c|}
\hline \multirow{4}{*}{2} & \multirow{4}{*}{ Sleep Quality(PSQI scores) } & $<5$ & $12(63.2 \%)$ & $5(35.7 \%)$ & $2(5.1 \%)$ & $1(6.3 \%)$ & \multirow{3}{*}{$\chi^{2}=34.07 ; p<0.001$} \\
\hline & & $5-10$ & $7(36.8 \%)$ & $8(57.1 \%)$ & $22(56.1 \%)$ & $8(50.0 \%)$ & \\
\hline & & $>10$ & 0 & $1(7.1 \%)$ & $15(38.5 \%)$ & $7(43.8 \%)$ & \\
\hline & & Mean PSQI \pm SD & $4.53 \pm 1.50$ & $6.07 \pm 2.46$ & $8.82 \pm 2.70$ & $9.50 \pm 3.14$ & $F=16.84 ; p<0.001$ \\
\hline
\end{tabular}

\section{References}

[1] Cain N. Gradisar M. Electronic media use and sleep in school-aged children and adolescents: a review. Sleep Med. 2010; 11:735-42.

[2] Lemola S. Perkinson-Gloor N. Brand S. DewaldKaufmann JF. Grob A. Adolescents' electronic media use at night, sleep disturbance, and depressive symptoms in the smartphone age. J Youth Adolesc. 2015;44:405-18. Link
[3] Chaput JP, Gray CE, Poitras VJ, et al. Systematic review of the relationships between sleep duration and health indicators in school-aged children and youth. ApplPhysiolNutrMetab. 2016;41(6 Suppl 3):S266S282. Link

[4] Chaput JP, Gray CE, Poitras VJ, et al. Systematic review of the relationships between sleep duration and health indicators in the early years (0-4 years) BMC Public Health. 2017;17(Suppl 5):855. Link

[5] St-Onge MP, Grandner MA, Brown D, et al. Sleep duration and quality: impact on lifestyle behaviors and cardiometabolic health: a scientific statement from the 
American Heart Association. Circulation. 2016;134(18):e367-386. Link

[6] Buysse DJ. Sleep health: can we define it? Does it matter? Sleep. 2014;37(1):9-17. Link

[7] Gruber R, Carrey N, Weiss SK, et al. Position statement on pediatric sleep for psychiatrists. J Can Acad Child Adolesc Psychiatry. 2014;23(3):174-195. Link

[8] Hirshkowitz M, Whiton K, Albert S, Alessi C, Bruni O, Doncarlos L, et al. National Sleep Foundation's sleep time duration recommendations: Methodology and Results Summary. Sleep Health 2015; 1: 40-43.

[9] Daniel WW. Biostatistics: A Foundation for Analysis in the Health Sciences. $7^{\text {th }}$ edition. 1999, New York: John Wiley \& Sons.

[10] Brinkman JE, Reddy V, Sharma S. Physiology, Sleep. [Updated 2020 Apr 29]. In: StatPearls [Internet]. Treasure Island (FL): StatPearls Publishing; 2020 Jan-. Available from: https://www.ncbi.nlm.nih.gov/books/NBK482512/

[11] Watson NF, Badr MS, Belenky G, et al. Joint Consensus Statement of the American Academy of Sleep Medicine and Sleep Research Society on the recommended amount of sleep for a healthy adult: methodology and discussion. Sleep. 2015; 38(8):11611183.

[12] Institute of Medicine, Committee on Sleep Medicine and Research, Board on Health Sciences Policy. Sleep Disorders and Sleep Deprivation: An Unmet Public Health Problem. Washington, DC: National Academies Press; 2006.

[13] Gutin I. In BMI We Trust: Reframing the Body Mass Index as a Measure of Health. Soc Theory Health. 2018; 16(3):256-271.

[14] Hall DM, Cole TJ. What use is the BMI?. Arch Dis Child. 2006;91(4):283-286. 